\title{
Disruption of the Circadian Output Molecule Prokineticin 2 Results in Anxiolytic and Antidepressant-like Effects in Mice
}

\author{
Jia-Da Li, ${ }^{1,2}$, Wang-Ping Hu ${ }^{1,2}$ and Qun-Yong Zhou*,1 \\ 'Department of Pharmacology, University of California, Irvine, CA, USA
}

\begin{abstract}
Disrupted circadian rhythms are strictly associated with mood disorders. The suprachiasmatic nucleus (SCN) is the master pacemaker that drives circadian rhythms in mammals. However, the underlying molecular connections of circadian rhythm and mood disorders are still poorly understood. Prokineticin 2 (PK2) is a signaling molecule that is critical for transmitting the circadian rhythms from the SCN. Previously, it is has been shown that the receptor for PK2 is expressed in virtually all of the primary SCN target areas, most of which are also involved in the mood regulation. In the current study, we investigated the role of PK2 in the regulation of anxiety and depressionrelated behaviors. Intracerebroventricular (ICV) infusion of PK2 increased anxiety-like behavior as assessed by light-dark box. ICV delivery of PK2 also led to increased depression-like behavior in the forced swimming test. Conversely, mice lacking the PK2 gene (PK2 $2^{-1-}$ mice) displayed significantly reduced anxiety and depression-like behaviors. Furthermore, $P K 2^{-1-}$ mice showed impaired responses to new environments in terms of locomotor activity, arousal, body temperature, and food intake. Our studies, thus, indicate that PK2 signaling plays a critical role in the stress-related traits in mice, and establish a possible molecular link between circadian rhythms and mood regulation.

Neuropsychopharmacology (2009) 34, 367-373; doi:I0.1038/npp.2008.6I; published online 23 April 2008
\end{abstract}

Keywords: prokineticin 2; anxiety; depression; circadian; stress; hypothalamus-pituitary-adrenal axis

\section{INTRODUCTION}

Circadian rhythms are prominent in a variety of behavioral and physiological processes, including sleep/wake cycles, food intake, hormone level, and even emotional conditions (Hastings et al, 2007; Reppert and Weaver, 2002). Disrupted circadian rhythms are strictly associated with many mood disorders, such as bipolar disorders, major depression, and seasonal affective disorder (McClung, 2007; Turek, 2007). Most severe depression symptoms typically occur in the morning hours (Rusting and Larsen, 1998), and depression is more prevalent in geographic areas that receive little sunlight for extended periods of time (Booker et al, 1991). Seasonal affective disorder occurs only in the winter months when there are shorter days and a later dawn (Lam and Levitan, 2000; Magnusson and Boivin, 2003). In addition, many of the effective treatments for mood disorders, such as sleep deprivation therapy, bright light therapy as well as some pharmacological treatments, are either targeting or affecting the circadian systems (McClung, 2007). Moreover, some of the major hallmarks of mood disorders include disrupted circadian rhythms in sleep/wake, appetite, and

\footnotetext{
*Correspondence: Dr Q-Y Zhou, Department of Pharmacology, University of California, 19182 Jamboree Blvd, Irvine, CA 92697, USA, Tel: + I 949824 2232, Fax: + I 949824 4855,

E-mail: qzhou@uci.edu

${ }^{2}$ These authors contributed equally to this work.

Received I4 January 2008; revised 23 February 2008; accepted 18 March 2008
}

social activity (Boivin, 2000; Bunney and Bunney, 2000; Grandin et al, 2006; Lenox et al, 2002). Although the association between mood disorders and circadian rhythms has been known for many years, the underlying molecular mechanisms have started to emerge only very recently.

The mammalian suprachiasmatic nucleus (SCN) is the master pacemaker that drives diverse circadian rhythms (Reppert and Weaver, 2002). Multiple interlocked transcriptional and translational loops consisting of a number of clockwork genes underlie the molecular mechanisms for the SCN clock. The Clock/Bmall complex transcriptionally activates clock-controlled genes, including periods (Pers) and cryptochromes (Crys), the products of which act as repressors by interacting directly with Clock/Bmall (Reppert and Weaver, 2002). Single-nucleotide polymorphism (SNP) analysis has identified certain clock genes, such as Clock, Bmal1, and Per3, which are associated with mood disorders (Benedetti et al, 2003; Mansour et al, 2006; Nievergelt et al, 2006). Recently, a number of behavioral studies have examined the involvement of central circadian pacemaker on measurements of anxiety and depression with either SCN lesion or genetic mutant animal models. Bilateral SCN lesions in rats was found to have an antidepressant-like effect in a forced swimming test (Tataroglu et al, 2004), suggesting that disruption of the SCN has a protective effect on depression-like behavior. Antidepressant agomelatine, which is normally effective in reducing the depression and anxiety-like behavior following social defeat, was not effective in the SCN-lesioned animals 
(Tuma et al, 2005). Furthermore, mice harboring a mutation in the Clock gene were shown to display reduced depression-like behavior in the forced swimming and learned helplessness tests, as well as reduced anxiety or increased risk-taking behavior in several measures (Easton et al, 2003; Roybal et al, 2007). Transgenic mice overexpressing GSK $3 \beta$, a circadian modulator, are hyperactive and have reduced immobility in the forced swimming test, indicating lower depression-like behavior (Prickaerts et al, 2006). Thus, these studies have implicated the link between mood regulation and certain circadian genes.

We have previously demonstrated that prokineticin 2 (PK2) is an output molecule for the SCN clock to communicate with primary SCN targets (Cheng et al, 2002, 2005; Li et al, 2006; Zhou and Cheng, 2005). The expression of $P K 2$ in the SCN is activated by Clock/Bmall complex, and suppressed by Pers and Crys (Cheng et al, 2002). PK2-deficient mice exhibited reduced rhythmicity for a variety of physiological and behavioral parameters, including sleep/wake cycle, activity, body temperature, circulating glucocorticoid, and glucose levels, as well as the expression of peripheral clock genes (Li et al, 2006). Disruption of the receptor for PK2 (PKR2), a G-proteincoupled receptor, also results in similarly damped circadian rhythms in locomotor activity and body temperature (Prosser et al, 2007). PKR2 is expressed in virtually all known primary SCN targets (Cheng et al, 2002), some of which are also involved in the mood regulation, such as the amygdala, the lateral septum, and the paraventricular nucleus (Cheng et al, 2006). Thus, as an SCN output signal, PK2 may serve as a molecular link between circadian rhythms and mood regulation. Here, we investigated the functional role of PK2 in anxiety and depression-like behaviors as well as stress response.

\section{MATERIALS AND METHODS}

\section{Animals}

$P K 2^{-1-}$ mice were generated by homologous recombination as previously described (Li et al, 2006). $P K 2^{-/-}$mice and their littermate wild-type (WT) mice of C57BL/6 $\times 129 /$ Ola hybrid background were used in all experiments. Mixed female and male mice (approximately 1:1) 3-5 months of age were used in all experiments unless otherwise indicated. The anxiety and depression-like behaviors were carried out between 1400 and 1700 hours under a 12-h light/ 12-h dark condition (light on at 0700 hours and light off at 1900 hours), when PK2 is highly expressed in the SCN (Cheng et al, 2002). All procedures regarding the care and use of animals are in accordance with the Institutional Guidelines.

\section{Anxiety-like Behaviors}

The anxiety-like behaviors were measured with elevated plus maze and light-dark box. The elevated plus maze utilizes the innate fear of elevated open places for rodents. Animals with reduced anxiety will spend relatively more time in the open arms (Crawley, 1999). The plus maze consisted of two open $(30 \times 5 \mathrm{~cm})$ and two wall-enclosed arms $(30 \times 5 \times 15 \mathrm{~cm})$ connected by a central platform
$(5 \times 5 \mathrm{~cm})$. The apparatus was elevated $75 \mathrm{~cm}$ above the floor (Koster et al, 1999). Behavioral testing began by placing a mouse in the central area facing a closed arm, in which the animal usually enters first. Exploratory behavior was monitored over a period of $5 \mathrm{~min}$. Number of entries into open arms, time traveled in open and closed arms, general activity, and latency until the first open-arm entry were recorded and quantified. Entries were defined as four paws of an animal entering a new zone. The risk assessment was reflected in head-dipping, an exploratory forward head/ shoulder movement over the side of the open arms and down toward the floor.

The light-dark box utilizes the natural aversion of rodents to the bright light and open field, and animals with reduced anxiety will spend relatively more time in the lit compartment (Crawley, 1999). The light-dark box was divided into a lit compartment $(30 \times 20 \times 25 \mathrm{~cm}$, illumination 400 lux $)$ and a dark compartment $(15 \times 20 \times 25 \mathrm{~cm})$ connected by a $4-\mathrm{cm}^{2}$ tunnel (Koster et al, 1999). The experiment was started by placing the animal in the dark compartment. Numbers of transitions, total time spent in the lit compartment, and latency until the first exit were recorded on video and quantified for $10 \mathrm{~min}$.

\section{Porsolt's Forced Swim Test}

Animals were placed individually in cylinders (height $25 \mathrm{~cm}$, diameter $11 \mathrm{~cm}$ ) filled with $8-\mathrm{cm}$-deep water (temperature $22 \pm 1{ }^{\circ} \mathrm{C}$ ) for $6 \mathrm{~min}$. The period of immobility, which was defined as no volitional body or limb movement, was recorded. In Porsolt's forced swim test, the animals try to escape at early phase. After unsuccessful initial escapes, animals may stop swimming and float on the surface of the water (eg, immobility). The immobility is interpreted as a sign of depression-like behavior as antidepressants decrease the time of immobility (Porsolt et al, 1977).

\section{Learned Helplessness Following Inescapable Shock}

The learned helplessness paradigm is a depression model, in which animals are exposed to uncontrollable stress (eg, electroshocks) and, subsequently, develop coping deficits in escapable situations (Chourbaji et al, 2005). Mice were placed in a chamber in which they could not escape (Coulbourn Instruments, Allentown, PA) and received two shocks (5-s duration at $0.3 \mathrm{~mA}$ ) per min for $1 \mathrm{~h}$, and, then, they were returned to their home cage. This was repeated on the second day. On the third day, the automatic guillotine door opened concurrent with presentation of each foot shock (one 0.3-mA, 30-s shock per min for $30 \mathrm{~min}$ ), allowing the mice to escape into the non-shock chambers (Roybal et al, 2007). Failure to escape during a 30-s shock period was counted as an 'escape failure.' The percentage of escape failure was then calculated. Escape failure is interpreted as 'behavioral despair' and antidepressants reduce the percentage of escape failure (Chourbaji et al, 2005).

\section{Core Body Temperature and Locomotion Measurement}

A radio transmitter device (G2 E-mitter; Mini-Mitter, Sunriver, OR) used to measure body temperature and 
locomotor activity was implanted in the abdominal cavity by sterile technique under general anesthesia. Body temperature and locomotor activity were recorded by a receiver board (ER-4000 energizer receiver; Mini-Mitter) underneath the cage and were stored in a personal computer every $5 \mathrm{~min}$. The mice were allowed to recover for at least 2 weeks before the experiments. The ambient temperature was constant at $21^{\circ} \mathrm{C}$. The cage change was done at zeitgeber time (ZT) 4 (zeitgeber time is measured in hours after the light has been turned on in a 12-h light/12-h dark cycle) by transferring the mouse into a new cage with food and water where body temperature and locomotion were monitored for the following $2 \mathrm{~h}$.

\section{Food Intake}

Food intake measurement was performed using a Comprehensive Lab Animal Monitoring System (CLAMS; Columbus Instruments, Columbus, Ohio). Feeding data were collected every $10 \mathrm{~min}$ for each mouse over a period of 5 days. The daily food intake was the total food consumed during $24 \mathrm{~h}$.

\section{Intracerebroventricular Infusion}

A 26-gauge stainless steel indwelling cannula (Plastics One, Roanoke, VA) was implanted $2.6 \mathrm{~mm}$ below the skull surface into the lateral ventricle ( $1.1 \mathrm{~mm}$ lateral to bregma) of male mice (C57BL/6) as described previously (Ferguson et al, 2001). A dummy cannula was inserted to maintain potency. Injections were performed using a 33-gauge stainless steel injector attached to PE-10 tubing fitted to a $10-\mu 1$ Hamilton syringe. Injections began 7-10 days after mice recovered from surgery.

\section{Determination of Corticosterone Level}

Male WT and $P K 2^{-1-}$ mice were housed individually before collection of blood samples. For basal levels, blood samples were collected by retro-orbital eye bleeding within $45 \mathrm{~s}$ of initial disturbance of the cages at ZT 1 . Blood samples were collected either immediately or $90 \mathrm{~min}$ after stress (3-min cold-water swimming). Plasma corticosterone levels were determined using a radioimmunology assay kit (ICN Biomedicals, Costa Mesa, CA) according to the instructions.

\section{RESULTS}

Intracerebroventricular Infusion of PK2 Increases the Anxiety and Depression-like Behaviors

To investigate the role of PK2 in the mood regulation, we first examined the effects of PK2 injected by intracerebroventricular (ICV) on the anxiety and depression-like behaviors. As shown in Figure 1a, PK2 infusion led to significantly less time spent in the lit box in a light-dark box assay, without a significant effect on general activity, as reflected in the total number of transitions. Moreover, PK2 infusion significantly increased the time spent in
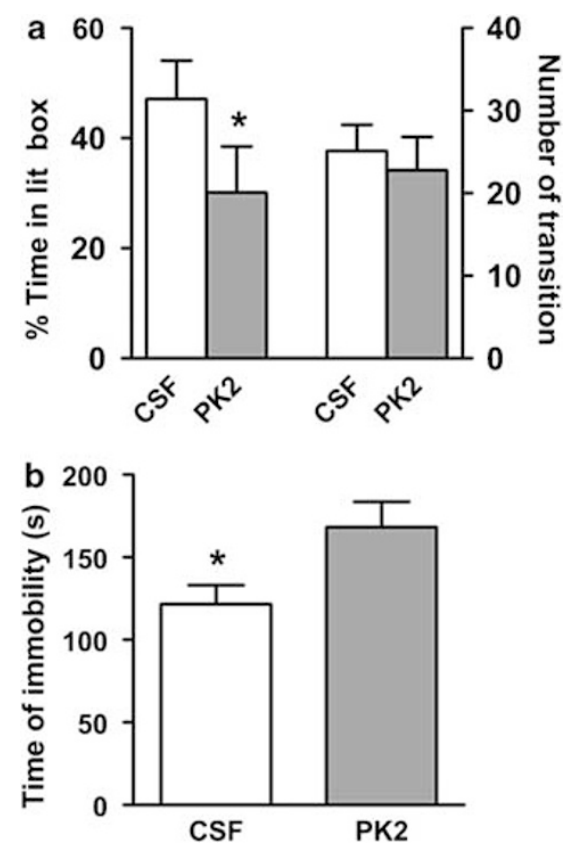

Figure I Effect of ICV infusion of PK2 on anxiety and depression-like behaviors. (a) Artificial cerebrospinal fluid (CSF) or $4 \mu \mathrm{g}$ of PK2 was infused ICV into mice. Anxiety-like behavior was monitored with a light-dark box assay I h after infusion, $n=12$ mice/group. (b) CSF or $4 \mu \mathrm{g}$ of PK2 was infused ICV into mice. Immobility in a forced swimming test was measured I h after infusion, $n=12$ mice/group; $* P<0.05$; Student's $t$-test. Error bars, SEM.

immobility during a forced swimming test (Figure $1 \mathrm{~b}$ ), a sign of depression-like behavior (Porsolt et al, 1977).

\section{Altered Response of $\mathrm{PK}^{-/-}$Mice to New Environments}

We have previously shown that $P K 2^{-/-}$mice displayed less arousal increase in response to a cage change ( $\mathrm{Hu}$ et al, 2007). We also monitored core body temperature and locomotor activity in WT and $P K 2^{-1-}$ mice in response to a cage change at ZT 4 . As shown in Figure $2 \mathrm{a}$ and $\mathrm{b}$, the cage change initially increased body temperature and locomotor activity in both WT and $P K 2^{-\prime-}$ mice. However, $P K 2^{-/-}$ mice habituated to the novel environments in a significantly shorter time than WT mice. During the period from 45 to $90 \mathrm{~min}$ after the cage change, the body temperature of $P K 2^{-1-}$ mice was significantly lower than that of WT mice. Similarly, the locomotor activity of $P K 2^{-1-}$ mice between 40 and $75 \mathrm{~min}$ after cage change was significantly smaller than that of WT mice.

Similarly, we observed an altered response in $P K 2^{-/-}$ mice while monitoring the food intake with a Comprehensive Laboratory Animal Monitor System (CLAMS; Columbus Instruments). When transferred into the new environment, that is, CLAMS chamber, the food intake of WT mice was significantly suppressed in the first 2 days, and then gradually increased to their steady-state levels (Figure 2c). However, $\mathrm{PK}^{-1-}$ mice did not exhibit such a food intake difference between day 1 and days 3-4 (Figure 2c). Taken together, these results consistently demonstrate that $P K 2^{-{ }^{-}}$mice show impaired responses to new environments in terms of activity, arousal, body temperature, and food intake. 

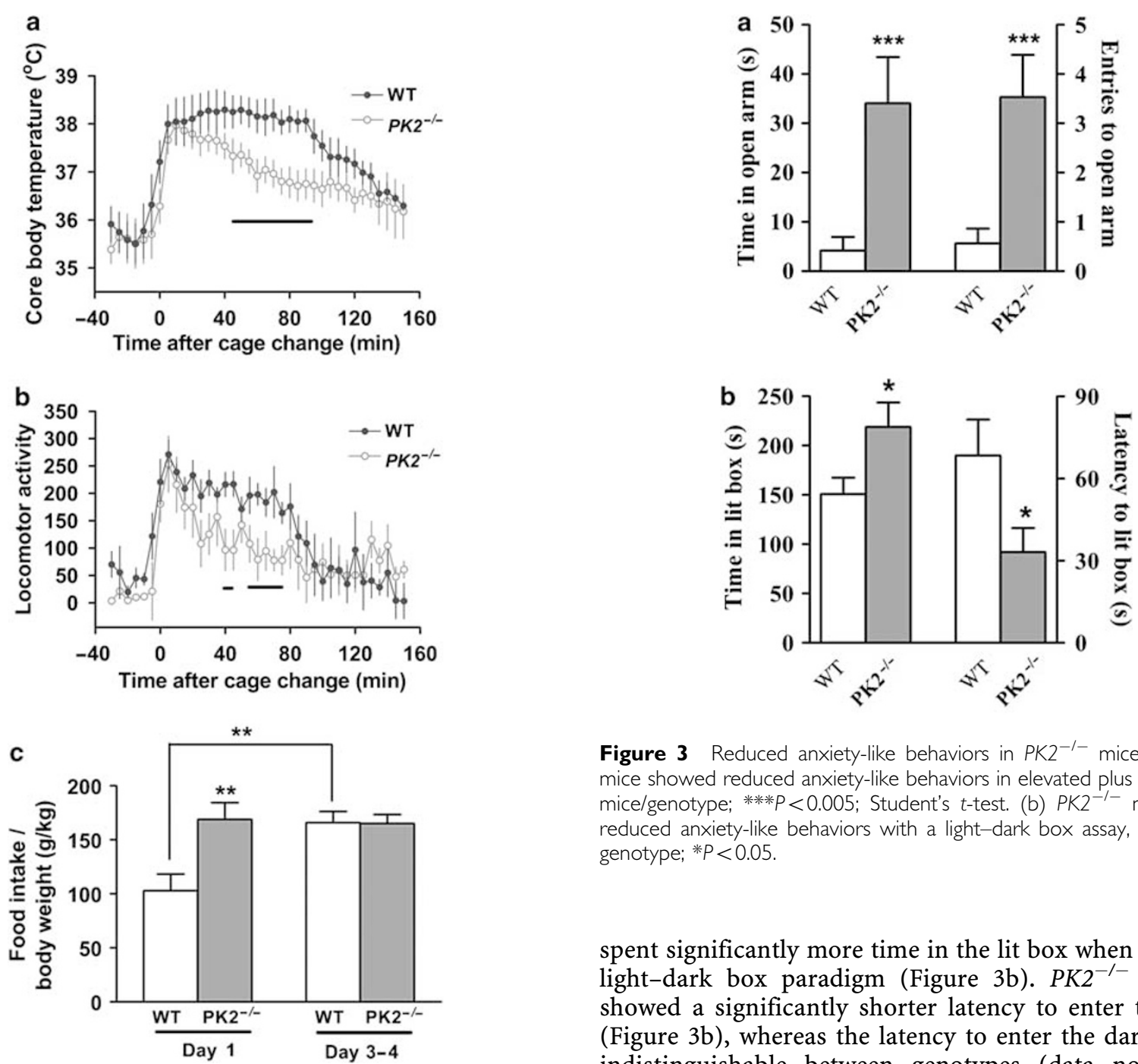

Figure 2 Altered adaptation of $P K 2^{-1-}$ mice to new environments. (a) The core body temperature before and following a cage change at ZT 4 in WT (blue closed circles) and $P K 2^{-1-}$ mice (red open circles) (genotype: $F(I)=55.57, P<0.000$ I, two-way ANOVA). (b) Locomotor activity before and following a cage change at ZT 4 in WT (blue closed circles) and $P K 2^{-1-}$ mice (red open circles) (genotype: $F(I)=20.19, P<0.000 I$, two-way ANOVA), $n=6$ mice/genotype. The lines under the curve of (a) and (b) indicate the P-values between genotypes are less than 0.05, Student's t-test. (c) The food intake of WT and $P K 2^{-1-}$ mice during day $I$ and days $3-4$ in CLAMS chambers, $n=12$ mice/genotype (genotype $x$ time, $F(I)=6.37, P<0.02$, two-way ANOVA; $* * P<0.01$; post hoc Bonferroni's t-test).

\section{Reduced Anxiety-like Behaviors in $P K 2^{-/-}$mice}

The impaired response of $\mathrm{PK}^{-/-}$mice to new environments suggested that they had a reduction in anxiety levels. We, therefore, quantified the anxiety-like behaviors with two standard paradigms: the elevated plus maze and the light-dark box. In the elevated plus maze assay, $P K 2^{-/-}$ mice spent significantly more time in the open arm (Figure 3a). Moreover, the total entries into open arm were significantly higher in $\mathrm{PK}^{-/-}$mice than WT mice (Figure 3a), whereas the numbers of head-dipping occurring from the center or the closed arms were indistinguishable between genotypes (data not shown). Consistent with our observations in the elevated plus maze, $P K 2^{-/-}$mice

spent significantly more time in the lit box when tested in a light-dark box paradigm (Figure $3 \mathrm{~b}$ ). $P K 2^{-1-}$ mice also showed a significantly shorter latency to enter the lit box (Figure $3 b$ ), whereas the latency to enter the dark box was indistinguishable between genotypes (data not shown). These results, thus, indicate that $P K 2^{-1-}$ mice display reduced anxiety-like behaviors.

\section{Reduced Depression-like Behaviors in $\mathrm{PK}^{-/-}$Mice}

Depression is an important symptom that frequently accompanies chronic stress and anxiety. We measured the depression-like behavior with a forced swimming test (Porsolt et al, 1977) and a learned helplessness test (Roybal et al, 2007). In both tests, $P K 2^{-/-}$mice showed a reduction in helpless behaviors as measured by immobile time in the forced swimming test and the percentage of escape failure in the learned helplessness test (Figure $4 \mathrm{a}$ and $\mathrm{b}$ ).

\section{Altered Stress-Induced Activation of Hypothalamus- Pituitary-Adrenal Axis in $P K 2^{-/-}$Mice}

The activation of hypothalamus-pituitary-adrenal (HPA) axis, which can be estimated by the elevated plasma corticosterone levels, is a critical integrator of stress response (Pawlak et al, 2003). Moreover, circulating glucocorticoid plays important roles in the feedback regulation of stress response (Tronche et al, 1999). To determine if $P K 2^{-/-}$mice have deficit in the HPA axis activation, we measured the circulating corticosterone levels 

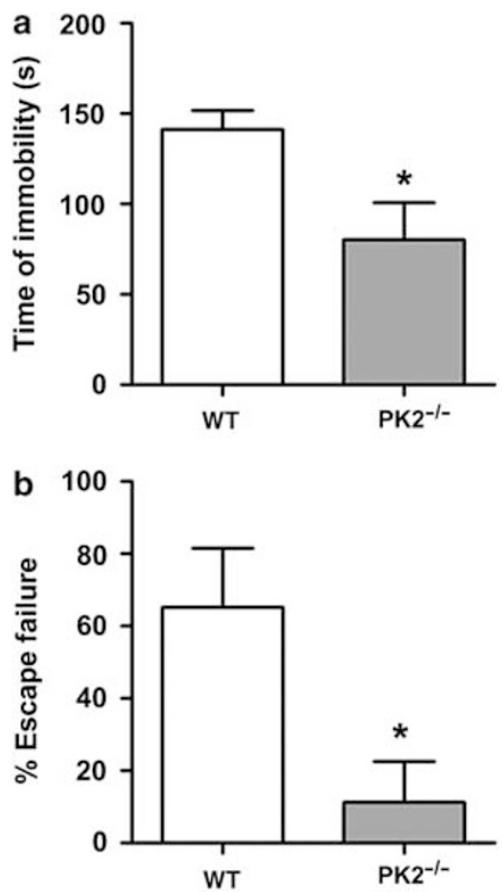

Figure 4 Reduced depression-like behaviors in $P K 2^{-1-}$ mice. (a) $P K 2^{-1-}$ mice showed reduced immobility in a forced swimming test, $n=15$ mice/ genotype; $* P<0.05$, Student's $t$-test. (b) $P K 2^{-1-}$ mice showed reduced escape failure in a learned helplessness test, $n=8$ mice/genotype; $* P<0.05$; Student's t-test. Error bars, SEM.

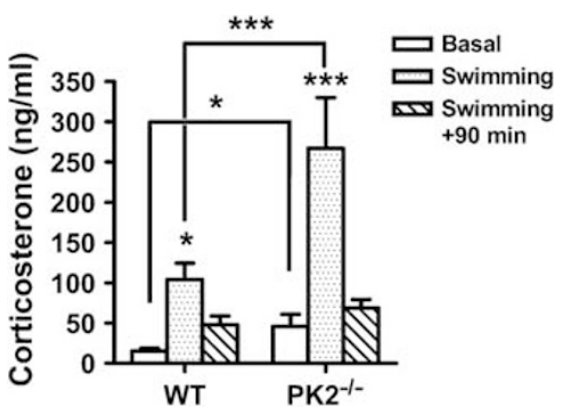

Figure 5 The hormonal response under stress in WT and $P K 2^{-1-}$ mice. The corticosterone levels in WT and PK2 ${ }^{-1-}$ mice before and after 3 min of cold-water swimming (genotype effect: $F(I)=13.56, P<0.00 \mid$; twoway ANOVA), $n=8-10$ mice/genotype; $* P<0.05$; $* * * *<<0.00$ I; post hoc Bonferroni's t-test. Error bars, SEM.

in $P K 2^{-1-}$ and WT mice before, immediately and $90 \mathrm{~min}$ after $3 \mathrm{~min}$ of cold-water swimming. As shown in Figure 5, 3 min of cold-water swimming led to a striking increase of the corticosterone level in both WT and $P K 2^{-/-}$mice. In fact, $P K 2^{-/-}$mice displayed an even greater increase of corticosterone level in response to cold-water swimming. At $90 \mathrm{~min}$ after stress, the corticosterone level in both genotypes returned to basal levels.

\section{DISCUSSION}

Single-nucleotide polymorphism analysis and studies with animal models that have disrupted circadian rhythms have indicated a molecular link between circadian rhythms and mood regulation (Curtis et al, 2007; McClung, 2007; Prickaerts et al, 2006; Roybal et al, 2007). Our findings here indicate that PK2, as an SCN circadian output factor, also plays a critical role in the regulation of stress-related traits. Central infusion of PK2 led to increase of anxiety and depression-like behaviors. In contrast, mice deficient in PK2 displayed reduced anxiety and depression-like behaviors. However, $P K 2^{-/-}$mice showed an exaggerated stressactivated HPA axis.

Interestingly, disrupted circadian clock is always associated with depression; however, $P K 2^{-1-}$ mice, SCNlesioned rats, and Clock mutant mice all displayed antidepressant-like phenotypes (Easton et al, 2003; Roybal et al, 2007; Tataroglu et al, 2004). Therefore, changes in the amplitude or period of the circadian pacemaker may not result in depression. It is possible that the elevated corticosterone level in $\mathrm{PK} 2^{-/-}$mice and SCN-lesioned rats during stressful conditions spare these animals from the inescapable stress. Corticosterone is the primary hormone that mobilizes the animals against the debilitating effects of stress and as such has stress-protective functions (Sapolsky et al, 2000). Administration of corticosterone has been shown to have an antidepressant effect in humans and reduce learned helplessness in adrenalectomized rats (DeBattista et al, 2000; Edwards et al, 1990). In addition to the reduced anxiety and depression, Clock mutant mice also showed hyperactivity, hyperhedonia, and increased preference for cocaine, mimicking manic symptoms (Roybal et al, 2007). However, $P K 2^{-/-}$mice are hypoactive (Li et al, 2006), and did not show increased preference to ethanol or sucrose (data not shown). The discrepancy between these two strains of mutant mice may arise from the following reasons: (i) PK2 is only one of the CLOCK target genes, the other target gene products, such as vasopressin and cardiotrophin-like cytokine may mediate the other functions (Jin et al, 1999; Kraves and Weitz, 2006). (ii) Clock is also expressed in other brain areas where PK2 is undetectable, such as the ventral tegmental area (VTA) (Roybal et al, 2007). Indeed, viral delivery of Clock into the VTA normalizes the hyperactivity in the Clock mutant mice (Roybal et al, 2007).

The circadian clock, stemmed from the SCN, plays an essential role in controlling the daily rhythm of circulating corticosterone (Buijs and Kalsbeek, 2001). The level of corticosterone exhibits a daily rhythm, with high level at the active phase. SCN lesion led to an elevated corticosterone level in the morning, whereas the evening corticosterone level is essentially unaltered (Buijs et al, 1993). Interestingly, SCN-lesioned rats also showed a higher stress-induced corticosterone level than the sham-operated controls (Buijs et al, 1993). Thus, Buijs et al (1993) proposed that factor(s) from the SCN suppress the corticosterone level under both basal and stressful situations. PK2 may be one of such factors as PK2 disruption results in elevated basal and stress-induced corticosterone level in the morning (Figure 5) (Li et al, 2006), when PK2 level peaks in the SCN (Cheng et al, 2002).

As for all studies using genetically engineered mice with constitutively inactivation of a specific gene, the data obtained in $P K 2^{-/-}$mice have to be interpreted with caution. Both compensatory process and developmental 
issue may contribute to the phenotype observed. Nevertheless, we consider the phenomena described here are mostly the direct effect of PK2 based on the following reasons. First, the phenotypes of $P K 2^{-/-}$mice shared many similarities with Clock mutant mice and SCN-lesioned rats, consistent with the fact that PK2 is an important SCN output factor. It is at least apparently not a compensatory process and developmental issues in the SCN-lesioned rats. Second, ICV injection of PK2 into WT mice increased the anxiety and depression, in sharp contrast to the decreased anxiety and depression in $P K 2^{-f-}$ mice. Third, $P K 2^{-1-}$ mice showed developmental deficiency in the olfactory bulb $(\mathrm{Ng}$ et al, 2005); however, olfactory bulbectomy leads to increased activity and depression-like behavior (Song and Leonard, 2005; Zueger et al, 2005), whereas $P K 2^{-/-}$mice are hypoactive and showed reduced depression-like behaviors. Fourth, the body temperature and locomotor activity of $P K 2^{-/-}$mice reached a similar level as WT controls after a cage change at ZT 4 (Figure 2a and b), indicating an intact stress perception in $P K 2^{-/-}$mice. This is further confirmed by an intact activation of HPA axis in $\mathrm{PK}^{-/-}$mice in response to stress.

It is possible that PK2 in other brain areas also involves in the mood regulation. PK2 is also expressed in the medial amygdala and the medial preoptical area, which may participate in the regulation of stress-related traits. Nevertheless, our data showed that PK2 plays an important role in the mood regulation, thus supported a possible molecular link between circadian rhythms and mood regulation. Targeting PK2/PKR2 system may be a new avenue for the treatment of the debilitating mood disorders.

\section{ACKNOWLEDGEMENTS}

We thank Rainer K Reinscheid, Chengkang Zhang, Alex G Lee, Michelle Y Cheng, Ryan Yoshimura, and Katherine J Burton for technical assistance and critical comments on the paper. This work was supported in part by grants from National Institutes of Health and NARSAD (R01MH67753).

\section{DISCLOSURE/CONFLICT OF INTEREST}

A provisional patent has been filed, with J-DL and Q-YZ as co-inventors. The authors declare, except for income received from our primary employer, that no financial support or compensation has been received from any individual or corporate entity over the past 3 years for research or professional service, and there are no personal financial holdings that could be perceived as constituting a potential conflict of interest.

\section{REFERENCES}

Benedetti F, Serretti A, Colombo C, Barbini B, Lorenzi C, Campori $\mathrm{E}$ et al (2003). Influence of CLOCK gene polymorphism on circadian mood fluctuation and illness recurrence in bipolar depression. Am J Med Genet B Neuropsychiatr Genet 123: 23-26.

Boivin DB (2000). Influence of sleep-wake and circadian rhythm disturbances in psychiatric disorders. J Psychiatry Neurosci 25: 446-458.
Booker JM, Hellekson CJ, Putilov AA, Danilenko KV (1991). Seasonal depression and sleep disturbances in Alaska and Siberia: a pilot study. Arctic Med Res (Suppl): 281-284.

Buijs RM, Kalsbeek A (2001). Hypothalamic integration of central and peripheral clocks. Nat Rev Neurosci 2: 521-526.

Buijs RM, Kalsbeek A, van der Woude TP, van Heerikhuize JJ, Shinn S (1993). Suprachiasmatic nucleus lesion increases corticosterone secretion. Am J Physiol 264: R1186-R1192.

Bunney WE, Bunney BG (2000). Molecular clock genes in man and lower animals: possible implications for circadian abnormalities in depression. Neuropsychopharmacology 22: 335-345.

Cheng MY, Bittman EL, Hattar S, Zhou QY (2005). Regulation of prokineticin 2 expression by light and the circadian clock. $B M C$ Neurosci 6: 17.

Cheng MY, Bullock CM, Li C, Lee AG, Bermak JC, Belluzzi J et al (2002). Prokineticin 2 transmits the behavioural circadian rhythm of the suprachiasmatic nucleus. Nature 417: 405-410.

Cheng MY, Leslie FM, Zhou QY (2006). Expression of prokineticins and their receptors in the adult mouse brain. J Comp Neurol 498: 796-809.

Chourbaji S, Zacher C, Sanchis-Segura C, Dormann C, Vollmayr B, Gass P (2005). Learned helplessness: validity and reliability of depressive-like states in mice. Brain Res Brain Res Protoc 16: 70-78.

Crawley JN (1999). Behavioral phenotyping of transgenic and knockout mice: experimental design and evaluation of general health, sensory functions, motor abilities, and specific behavioral tests. Brain Res 835: 18-26.

Curtis AM, Cheng Y, Kapoor S, Reilly D, Price TS, Fitzgerald GA (2007). Circadian variation of blood pressure and the vascular response to asynchronous stress. Proc Natl Acad Sci USA 104: 3450-3455.

DeBattista C, Posener JA, Kalehzan BM, Schatzberg AF (2000). Acute antidepressant effects of intravenous hydrocortisone and $\mathrm{CRH}$ in depressed patients: a double-blind, placebo-controlled study. Am J Psychiatry 157: 1334-1337.

Easton A, Arbuzova J, Turek FW (2003). The circadian Clock mutation increases exploratory activity and escape-seeking behavior. Genes Brain Behav 2: 11-19.

Edwards E, Harkins K, Wright G, Henn F (1990). Effects of bilateral adrenalectomy on the induction of learned helplessness behavior. Neuropsychopharmacology 3: 109-114.

Ferguson JN, Aldag JM, Insel TR, Young LJ (2001). Oxytocin in the medial amygdala is essential for social recognition in the mouse. J Neurosci 21: 8278-8285.

Grandin LD, Alloy LB, Abramson LY (2006). The social zeitgeber theory, circadian rhythms, and mood disorders: review and evaluation. Clin Psychol Rev 26: 679-694.

Hastings M, O’Neill JS, Maywood ES (2007). Circadian clocks: regulators of endocrine and metabolic rhythms. J Endocrinol 195: 187-198.

Hu WP, Li JD, Zhang C, Boehmer L, Siegel JM, Zhou QY (2007). Altered circadian and homeostatic sleep regulation in prokineticin 2-deficient mice. Sleep 30: 247-256.

Jin X, Shearman LP, Weaver DR, Zylka MJ, de Vries GJ, Reppert SM (1999). A molecular mechanism regulating rhythmic output from the suprachiasmatic circadian clock. Cell 96: 57-68.

Koster A, Montkowski A, Schulz S, Stube EM, Knaudt K, Jenck F et al (1999). Targeted disruption of the orphanin FQ/nociceptin gene increases stress susceptibility and impairs stress adaptation in mice. Proc Natl Acad Sci USA 96: 10444-10449.

Kraves S, Weitz CJ (2006). A role for cardiotrophin-like cytokine in the circadian control of mammalian locomotor activity. Nat Neurosci 9: 212-219.

Lam RW, Levitan RD (2000). Pathophysiology of seasonal affective disorder: a review. J Psychiatry Neurosci 25: 469-480.

Lenox RH, Gould TD, Manji HK (2002). Endophenotypes in bipolar disorder. Am J Med Genet 114: 391-406. 
Li JD, Hu WP, Boehmer L, Cheng MY, Lee AG, Jilek A et al (2006). Attenuated circadian rhythms in mice lacking the prokineticin 2 gene. J Neurosci 26: 11615-11623.

Magnusson A, Boivin D (2003). Seasonal affective disorder: an overview. Chronobiol Int 20: 189-207.

Mansour HA, Wood J, Logue T, Chowdari KV, Dayal M, Kupfer DJ et al (2006). Association study of eight circadian genes with bipolar I disorder, schizoaffective disorder and schizophrenia. Genes Brain Behav 5: 150-157.

McClung CA (2007). Circadian genes, rhythms and the biology of mood disorders. Pharmacol Ther 114: 222-232.

Ng KL, Li JD, Cheng MY, Leslie FM, Lee AG, Zhou QY (2005). Dependence of olfactory bulb neurogenesis on prokineticin 2 signaling. Science 308: 1923-1927.

Nievergelt CM, Kripke DF, Barrett TB, Burg E, Remick RA, Sadovnick AD et al (2006). Suggestive evidence for association of the circadian genes PERIOD3 and ARNTL with bipolar disorder. Am J Med Genet B Neuropsychiatr Genet 141: 234-241.

Pawlak R, Magarinos AM, Melchor J, McEwen B, Strickland S (2003). Tissue plasminogen activator in the amygdala is critical for stress-induced anxiety-like behavior. Nat Neurosci 6: 168-174.

Porsolt RD, Le Pichon M, Jalfre M (1977). Depression: a new animal model sensitive to antidepressant treatments. Nature 266: 730-732.

Prickaerts J, Moechars D, Cryns K, Lenaerts I, van Craenendonck $\mathrm{H}$, Goris I et al (2006). Transgenic mice overexpressing glycogen synthase kinase 3beta: a putative model of hyperactivity and mania. J Neurosci 26: 9022-9029.

Prosser HM, Bradley A, Chesham JE, Ebling FJ, Hastings MH, Maywood ES (2007). Prokineticin receptor 2 (Prokr2) is essential for the regulation of circadian behavior by the suprachiasmatic nuclei. Proc Natl Acad Sci USA 104: 648-653.
Reppert SM, Weaver DR (2002). Coordination of circadian timing in mammals. Nature 418: 935-941.

Roybal K, Theobold D, Graham A, DiNieri JA, Russo SJ, Krishnan $\mathrm{V}$ et al (2007). Mania-like behavior induced by disruption of CLOCK. Proc Natl Acad Sci USA 104: 6406-6411.

Rusting CL, Larsen RJ (1998). Diurnal patterns of unpleasant mood: associations with neuroticism, depression, and anxiety. J Pers 66: 85-103.

Sapolsky RM, Romero LM, Munck AU (2000). How do glucocorticoids influence stress responses? Integrating permissive, suppressive, stimulatory, and preparative actions. Endocr Rev 21: 55-89.

Song C, Leonard BE (2005). The olfactory bulbectomised rat as a model of depression. Neurosci Biobehav Rev 29: 627-647.

Tataroglu O, Aksoy A, Yilmaz A, Canbeyli R (2004). Effect of lesioning the suprachiasmatic nuclei on behavioral despair in rats. Brain Res 1001: 118-124.

Tronche F, Kellendonk C, Kretz O, Gass P, Anlag K, Orban PC et al (1999). Disruption of the glucocorticoid receptor gene in the nervous system results in reduced anxiety. Nat Genet 23: 99-103.

Tuma J, Strubbe JH, Mocaer E, Koolhaas JM (2005). Anxiolytic-like action of the antidepressant agomelatine (S 20098) after a social defeat requires the integrity of the SCN. Eur Neuropsychopharmacol 15: 545-555.

Turek FW (2007). From circadian rhythms to clock genes in depression. Int Clin Psychopharmacol 22(Suppl 2): S1-S8.

Zhou QY, Cheng MY (2005). Prokineticin 2 and circadian clock output. FEBS J 272: 5703-5709.

Zueger M, Urani A, Chourbaji S, Zacher C, Roche M, Harkin A et al (2005). Olfactory bulbectomy in mice induces alterations in exploratory behavior. Neurosci Lett 374: 142-146. 